\title{
VIOLÊNCIA SEXUAL E JUSTIÇA DE TRANSIÇÃO NO BRASIL: POSSIBILIDADE DE RECONHECIMENTO DESDE UMA PERSPECTIVA DE GÊNERO
}

\author{
SEXUAL VIOLENCE AND TRANSITIONAL JUSTICE IN BRAZIL: A \\ POSSIBILITY OF RECOGNITION FROM A GENDER PERSPECTIVE
}

\author{
${ }^{1}$ Rosa Maria Zaia Borges \\ ${ }^{2}$ Simone Schuck da Silva
}

\section{RESUMO}

Propõe-se o reconhecimento da perspectiva de gênero nos crimes sexuais cometidos durante a ditadura civil-militar brasileira (1964-1985). A partir da justiça de transição e da criminologia feminista, questiona-se os mecanismos utilizados para investigar os crimes cometidos no período, atenta-se para a possibilidade de revitimização face à inadequação desses métodos e convoca ao desvelamento do posicionamento ideológico do Estado nas violências sexual e de gênero. $\mathrm{O}$ objetivo é diagnosticar a ausência da perspectiva nos estudos dos crimes sexuais cometidos durante o regime e na reconstrução da memória e da verdade, pilares da justiça de transição, para projetar perspectivas mais justas.

Palavras-chave: Violência sexual, Justiça de transição, Gênero, Criminologia feminista

\section{ABSTRACT}

It is proposed the recognition of the gender perspective in sexual crimes committed during the Brazilian civil-military dictatorship (1964-1985). From the transitional justice and feminist criminology, we question the mechanisms used to investigate crimes committed in the period, emphasize the possibility of victimization due to the inadequacy of these methods and call the unveiling of the ideological position of the state in sexual and gender violence. The goal is to diagnose the lack of perspective in studies of sexual crimes committed during the regime and in the reconstruction of memory and truth, transitional justice pillars, to design more equitable perspectives.

Keywords: Sexual violence, Transitional justice, Genre, Feminist criminology

\footnotetext{
${ }^{1}$ Doutora em Direito pela Universidade de São Paulo -USP, São Paulo. Professora Adiunta pelo Centro Universitário Ritter dos Reis -UNIRITTER, Porto Alegre, Rio Grande do Sul, (Brasil) Email: tutortreinamneto@ gmail.com

${ }^{2}$ Mestranda em Direito Público pela Universidade do Vale do Rio dos Sinos -UNISINOS, São Leopoldo, Rio Grande do Sul. Advogada pela Ordem dos Advogados do Brasil - Seccional Rio Grande do Sul -OAB/RS, Rio Grande do Sul, (Brasil).
} 


\section{A TÍTULO DE INTRODUÇÃO: SOBRE O QUE NÃO SE PERMITE FALAR}

"O corpo [da mulher] converteu-se em um campo de batalha no qual é cometida a violência mais brutal". Esta é uma das impactantes conclusões a que nos expõe um informe de 2004 da Anistia Internacional. O informe diz respeito especificamente ao quadro generalizado de violência sexual presente no conflito armado colombiano, mas poderia, salvo uma ou outra particularidade, ser tomado como um retrato do que foram as práticas generalizadas e institucionalizadas de violência (aqui incluídas em todas as suas formas) durante os períodos ditatoriais na América Latina, em particular as diversas formas de violência sexual que se produziram nesses contextos. Tal violência, algumas vezes, alcançou proporções assombrosas como abrir as barrigas das mulheres grávidas para extrair o feto. "Não deixar nem a semente", uma expressão que remonta às atrocidades perpetradas durante La Violencia nos anos 50, mas ainda usada nos dias de hoje, reflete a extrema crueldade envolvida (INTERNATIONAL AMNESTY, 2004).

Prática corrente nos conflitos armados ao redor do mundo, a violência sexual na América Latina, em seus conflitos armados ou em seus regimes ditatoriais, não foge à regra. Tal realidade foge ao previsto no direito internacional dos direitos humanos e no direito internacional humanitário, que proíbem qualquer tipo de discriminação ou restrição de direitos tomando o sexo por base, assim como o direito internacional humanitário, desde a Primeira Guerra Mundial, tem desenvolvido normas para coibir todo tipo de maus-tratos, inclusive violação sexual ${ }^{1}$. Desde então, a violação sexual, cometida durante um conflito armado, passou a ser concebida como "crime de guerra". Mais tarde, quando cometida em determinadas condições, tal violência passa a ser considerada também "crime contra a humanidade".

A jurisprudência internacional já firmou entendimento de que a violência sexual constitui uma forma de tortura se cometida por agente público, ou com sua aquiescência, consentimento ou instigação, com a intenção de obter informação, castigar, intimidar, humilhar ou discriminar a vítima ou terceira pessoa. Bastante consistente a jurisprudência construída nos últimos anos por tribunais ad hoc como o Tribunal Penal Internacional para a antiga Iugoslávia $^{2}$ e o Tribunal Penal Internacional para Ruanda que condenaram, por crimes

\footnotetext{
${ }^{1}$ Cf. o artigo 27 da IV Convenção de Genebra, os artigos 75 e 76 do Protocolo Adicional I às Convenções de Genebra e o artigo $4^{\circ}$ do Protocolo Adicional II às Convenções de Genebra.

2 ICTY, Appeal Chamber, Prosecutor v Kunarac et. al, 12 June 2002, parágrafo 151: “O Tribunal de Apelação, portanto, defende que dor física ou sofrimento severos, físicos ou mentais das vítimas não podem ser contestados
} 
contra a humanidade e crimes de guerra, autores de diversos atos de violência sexual, inclusive estupro e escravidão (BANKS, 2005).

A Corte Interamericana de Direitos Humanos decidiu que uma violação sexual pode constituir tortura mesmo quando consista em um só fato ou ocorra fora de instalações estatais, inclusive no domicîlio da vítima, desde que presentes os requisitos previstos na Convenção Interamericana para Prevenir e Punir a Tortura: intencionalidade; gravidade do sofrimento; e finalidade do ato (Caso Fernández Ortega e outros vs. México, Caso Rosendo Cantú e outra vs. México). Ainda, conforme o artigo $7^{\circ}$, g, do Estatuto de Roma do Tribunal Penal Internacional, quando a violência é praticada no quadro de um ataque generalizado ou sistemático contra a população civil, essa grave violação de direitos humanos adquire a qualidade de crime contra a humanidade. Afora isso, porque o estupro cometido por agentes estatais está abrangido pela definição de tortura, integra o rol de atos criminosos que estão sujeitos à jurisdição universal.

Ao discutir as novas formas da qual se revestem os conflitos armados contemporâneos, Segato (2013) denomina de "escritura no corpo das mulheres" as estratégias dos grupos em disputa e relembra, ainda, a necessidade de permanentemente reafirmar, portanto, que estes não são crimes de motivação sexual, como insistem em dizer as autoridades para privatizar e, dessa forma, banalizar este tipo de violência junto ao senso comum da opinião pública. São crimes de guerra, de uma guerra que deve ser urgentemente redefinida, analisada com novo enfoque e a partir de outros modelos, e incorporada com novas categorias jurídicas, em especial no campo dos direitos humanos e do direito humanitário (SEGATO, 2014).

Daí a defesa pela incorporação de um olhar desde a perspectiva de gênero ao estudo do terrorismo de Estado, pois assim pode-se contribuir para tornar visível o impacto diferenciado sobre as mulheres das práticas de violência política. Tal perspectiva incide não apenas na conceituação legal das condutas, mas também nos processos de verdade e nas políticas de justiça, memória e reparação, pilares de uma efetiva justiça de transição. Para Sonderéguer, Correa, Cassino e González, esse olhar não diz respeito apenas à memória, mas ancora no presente. A lógica de dominação ligada aos intercâmbios sexuais persiste até hoje nas mais diversas situações de detenção e prisão. De acordo com as autoras, o questionamento em torno da violência sexual sistemática e da tortura é uma instância possível para pensar as

e que o Tribunal de Julgamento concluiu com bom-senso que a dor ou o sofrimento era suficiente para caracterizar os atos dos apelantes, como atos de tortura" (tradução nossa). 
situações de violência estruturadas sobre as relações de poder entre os gêneros na atualidade (SONDERÉGUER; et al., 2014).

Inserida na lógica da tortura e estruturada na hierarquia de gênero e sexualidade, a violência sexual relatada por sobreviventes da ditadura militar constitui abuso de poder considerado como a faculdade ou a possibilidade do agente estatal infligir sofrimento, mas também a permissão (explícita ou não) para fazê-lo. De acordo com o Relatório da Comissão Nacional da Verdade no Brasil, foi assim que, de modo rotineiro, nos espaços em que a tortura tornou-se um meio de exercício de poder e dominação total, a feminilidade e a masculinidade foram mobilizadas para perpetrar a violência, rompendo todos os limites da dignidade humana.

Na América Latina, há equipes de investigações recentemente constituídas em diversos países para estudar os crimes sexuais ocorridos nos conflitos armados internos, criando categorias forenses e jurídicas para apreender, investigar e processar esse tipo específico de violência como crimes de guerra (SEGATO, 2014).

Um caso emblemático e que esse ano teve um desfecho a ser comemorado diz respeito à violência sistemática contra as mulheres indígenas como componente central do conflito na Guatemala. Ali, forças militares atuando para-estatalmente atacaram as mulheres dos diversos povos maias que forma a maioria indígena desse país, submeteram-nas a atos de extrema crueldade e a violações sistemáticas que tornaram públicas e resultaram na estigmatização e no ostracismo dessas mulheres como forma de dissolução do tecido social. Em fevereiro do corrente ano, a condenação de dois dos agentes foi símbolo da vitória do desnudamento dessas práticas e da responsabilização e punição dos perpetradores da violência (ELÍAS, 2016).

Em outubro de 2011 apresenta-se, pela primeira vez no Uruguai, uma denúncia penal por violações e abusos sexuais cometidos durante o período ditatorial, realizada por um coletivo de 28 mulheres ex presas políticas. Nesse mesmo ano discutia-se publicamente sobre a possibilidade de prescrição dos delitos cometidos durante a ditadura, caracterizando a urgência pela apresentação das denúncias. No caso uruguaio, a repressão esteve caracterizada pelo encarceramento prolongado e a aplicação sistemática de torturas, por isso resulta mais chamativa ainda a demora em colocar em palavras os horrores cometidos e a impossibilidade da sociedade uruguaia assumir a escuta desses casos. Na Argentina, em 2010, um tribunal emitiu condenação por delitos desse tipo, reconhecendo assim sua especificidade (BAICA; FERNÁNDEZ, 2012). 
No Peru, a experiência da Comissão Nacional da Verdade é destacável, pois houve a preocupação de que os mecanismos de investigação focassem na questão específica da violência sexual e da violência de gênero. Além disso, o informe da Comissão Interamericana sobre o caso de Raquel Martín de Mejía contra o Peru é um caso emblemático, onde a Comissão conclui que por suas características a violação sexual a que foi submetida a senhora Mejía deveria ser considerada como tortura (MANTILLA, 2010).

No Brasil, ainda que o Relatório da Comissão Nacional da Verdade tenha apresentado diversos relatos de que a prática de crimes sexuais foi recorrente e sistematizada, esbarra-se na posição estatocêntrica do Supremo Tribunal Federal em considerar que a lei de Anistia não permite o processamento e julgamento dos crimes cometidos durante o regime ditatorial (vide julgamento da ADPF 153). Em nome da soberania, descumprem-se tratados e convenções das quais o país é signatário e, mais, descumpre-se sentença internacional da Corte Interamericana de Direitos Humanos (Caso Gomes Lund e outros), onde foi clara a posição em relação a tal documento jurídico interno: constitui-se enquanto obstáculo para a efetiva transição.

Cientes desse cenário, não há como fugir da realidade que convoca a uma necessária, senão urgente, tomada de posição em relação à percepção de que os crimes sexuais e de gênero praticados no passado reproduzem e reafirmam um lugar no processo de jurisdicionalização dessas práticas - o de sua privatização (para não dizer marginalização ou invizibilização). Apresenta-se, na sequência, uma possível abordagem crítico-teórica para assumir e enfrentar tal debate.

\section{COMO DIZER O NÃO DITO? A CRIMINOLOGIA FEMINISTA E O RECONHECIMENTO DA PERSPECTIVA DE GÊNERO}

Para propor o reconhecimento da perspectiva de gênero nos crimes sexuais cometidos durante a ditadura civil-militar brasileira, é necessário modificar as perspectivas científicas tradicionais. Construídas sobre as bases narrativas e as compreensões masculinas, as metodologias da criminologia tradicional não dão conta do panorama histórico das mulheres. Assim, é preciso definir, inicialmente, a perspectiva de gênero da qual se fala, para, então, analisar as violências sofridas pelas mulheres, contextualizando-as na ditadura aqui instaurada a partir de 1964 .

Joan Scott entende que tanto as palavras quanto as ideias que elas pretendem significar possuem uma história e que, portanto, são incapazes de um aprisionamento 
temporal e espacial. Dessa forma, para analisar gênero, a autora retoma-o como um conceito do pensamento ocidental, em que a impossibilidade de engessamento conceitual é ignorada e no qual o binarismo homem/mulher é deduzido como universal e atemporal (SCOTT, 1995).

A partir dessa crítica, é possível entender gênero como uma construção de saber sobre as diferenças sexuais, a qual está imbricada nas nossas relações de poder. Como uma percepção das diferenças anatômicas e comportamentais, o gênero está hieraquizado em um modo de pensar inflexível e dual. Scott não nega a existência de diferenças entre os corpos sexuados, mas analisa como os significados culturais são construídos e, portanto, hierarquizados a partir dessas diferenças:

\begin{abstract}
o termo "gênero" parece ter feito sua aparição inicial entre as feministas americanas, que queriam enfatizar o caráter fundamentalmente social das distinções baseadas no sexo. A palavra indicava uma rejeição ao determinismo biológico implícito no uso de termos como "sexo" ou "diferença sexual" (SCOTT, 1995, p. 72).
\end{abstract}

É possível identificar, assim, que o conceito de gênero surge para indicar uma construção social, algo dado de forma externa ao indivíduo a partir das relações que ele constrói na sua sociedade. Trata-se, portanto, de uma noção analítica relacional, tal qual classe e raça, vez que, "na gramática, o gênero é compreendido como uma forma de classificar fenômenos, um sistema socialmente consensual de distinções e não uma descrição objetiva de traços inerentes". Em suma, a autora propõe desenvolver o gênero como uma categoria analítica, um sistema de relações sociais, e o define a partir de duas partes em conexão: "o gênero é um elemento constitutivo de relações sociais baseadas nas diferenças percebidas entre os sexos" e também é "[...] uma forma primária de dar significado às relações de poder" (SCOTT, 1995, p. 72).

A primeira parte da definição de gênero implica quatro elementos interrelacionados, quais sejam, "os símbolos culturalmente disponíveis que evocam representações simbólicas"; os conceitos normativos capazes de expressar interpretações dos significados dos símbolos na tentativa de limitá-las; uma concepção política relacionada às instituições e à organização social; e, a identidade subjetiva (SCOTT, 1995, p. 86).

Em um primeiro momento, seria possível compreender que, no espaço jurídico, o gênero assume o lugar de categoria analítica através de um conceito normativo, em que há uma oposição binária fixa e o conceito de "mulher" é limitado pela legislação. Pode-se entender esse engessamento espaço-temporal como uma tentativa de proteção jurídica frente à constatação de uma vulnerabilidade histórica das pessoas que se percebem e que são percebidas como mulheres. 
Porém, é preciso compreender gênero como um campo em que o poder se articula. Trata-se de um conceito mais amplo, trazido à tona pela segunda parte da definição de Scott. É nesse sentido que o gênero produz a hierarquização das diferenças e, ao final, as violências de gênero:

Estabelecidos como um conjunto objetivo de referências, os conceitos de gênero estruturama percepção e a organização concreta e simbólica de toda a vida social. $\mathrm{Na}$ medida em que essas referências estabelecem distribuições de poder (um controle ou um acesso diferencial aos recursos mateeriais e simbólicos), o gênero torna-se implicado na concepção e na construção do próprio poder (SCOTT, 1995, p. 88).

A partir das análises de Joan Scott, é possível problematizar os mecanismos capazes de converter as diferenças de gênero em desigualdades, restringindo o acesso aos direitos da cidadania e o reconhecimento das mulheres como sujeitos sociais e políticos. Entendendo que as significações de gênero e poder se constroem reciprocamente, é mais fácil identificar como a categoria de gênero é tratada pelos agentes estatais durante o período ditatorial no Brasil. $\mathrm{O}$ poder institucionalizado por si só é atravessado pela hierarquia de gênero, vez que "o gênero é uma das referências recorrentes pelas quais o poder político tem sido concebido, legitimado e criticado" (SCOTT, 1995, p. 92). Porém, em uma perspectiva militar, em que se trabalham conceitos de guerra e masculinidade, o gênero se torna um marcador social ainda mais forte e capaz de justificar violências:

Como a violência se organiza através das hierarquias sociais e das relações sociais de poder - elas próprias constitutivas da sociedade, das identidades coletivas e individuais -, a estruturação baseada na hierarquia de gênero e sexualidade transparece na violência estatal do período explicitando, por exemplo, o caráter tradicionalmente sexista e homofóbico da formação policial e militar, que constrói o feminino como algo inferior e associa violência à masculinidade viril (CNV, 2014, p. 404).

Também atravessado por conceitos de raça, classe e orientação sexual, o gênero, como categoria de poder, permite sua mobilização para perpetração de violências. Com o objetivo de ofender a sua dignidade, as torturas tentavam constranger as pessoas às expectativas de seus papéis de gênero, o que ocorroria tanto por humilhações verbais como pela "feminilização" ou "homossexualização" simbólica do corpo violentado.

Estudando os relatos das vítimas dos crimes na ditadura, a Comissão Nacional da Verdade define violência como "uso arbitrário e discricionário da força e do poder pessoal, coletivo e/ou institucional, de modo a violar a dignidade humana. [...]. Pode assumir distintas formas: física, psicológica, moral, sexual, entre outras" (CNV, 2014, p. 418). 
Especificamente sobre o conceito de violência sexual, ainda amparadas no Relatório da Comissão Nacional da Verdade, pode ser encontrado o entendimento amplo da Organização Mundial da Saúde sobre violência sexual:

\begin{abstract}
quaisquer atos sexuais ou tentativas de realizar um ato sexual, comentários ou investidas sexuais não consentidos, atos para comercializar ou de outra forma controlar a sexualidade de uma pessoa através do uso da coerção [...]. Abrange toda ação praticada em contexto de relação de poder, quando o abusador obriga outra pes soa à prática sexual ou sexualizada contra a sua vontade, por meio da força física, de influência psicológica (intimidação, aliciamento, indução da vontade, sedução) ou do uso de armas e drogas (CNV, 2014, p. 418).
\end{abstract}

De posse destes dois conceitos, aqui analisados em caráter de complementariedade, e atentas aos relatos publicizados pelo referido Relatório, tem-se que a violência sexual adornou-se de práticas diversas de tortura nos espaços oficiais e não oficiais de repressão em funcionamento durante todo o regime ditatorial no Brasil. São identificados constrangimentos diretos à sexualidade, tanto com relação à orientação sexual das pessoas sequestradas, com muitas referências humilhantes à homossexualidade, como também através da colocação das mulheres em loci de identidades femininas tidas como ilegítimas (prostituta, adúltera, esposa desviante de seu papel, mãe desvirtuada etc.), tornando-as, portanto, merecedoras das violências sexuais sofridas. A violência se apresentava, ademais, não apenas como ameaças de estupros diretamente realizadas às mulheres, mas também a filhas e companheiras de homens militantes: "os torcionários entendiam a violação de seus corpos como uma possibilidade de humilhar os homens dos grupos políticos aos quais pertenciam" (CNV, 2014, p. 402 et seq.).

Mulheres foram violentadas sob o argumento de ilegitimidade de suas identidades, "ao mesmo tempo que foram tratadas a partir de categorias construídas como masculinas: força e resistência físicas". As referências ao não pertencimento das mulheres ao local político frequentemente eram reforçadas pelos papéis "naturalmente femininos" que foram frustrados pelas suas lutas: “[...] haviam se afastado de seus 'lugares de esposa e mãe' e ousado participar do mundo político, tradicionalmente entendido como masculino" (CNV, 2014, p. 402-404, passim).

Violências específicas às mulheres cisgênero também foram realizadas, tendo em vista que a gravidez, o parto e a amamentação foram utilizados para a humilhação:

Há relatos que mostram perícia distinta na tortura de grávidas, com a utilização de técnicas e cuidados específicos quando se pretendia evitar que abortassem ou quando pretendiamefetivar o aborto, ou mesmo quando esterilizar uma mulher era o objetivo (CNV, 2014, p. 411). 
Em outro momento do Relatório, a Comissão faz questão de explicitar que não apenas a penetração, anal, vaginal ou oral, não consentida no corpo torturado é capaz de caracterizar violência sexual, mas também qualquer forma de violência, agressão ou violência, física ou psicológica, que faça referência ao gênero ou sexualidade da pessoa.

\begin{abstract}
Além da penetração vaginal, anal e oral, também constituem violência sexual golpes nos seios; golpes no estômago para provocar aborto ou afetar a capacidade reprodutiva; introdução de objetos e/ou animais na vagina, pênis e/ou ânus; choque elétrico nos genitais; sexo oral; atos físicos humilhantes; andar ou desfilar nu ou seminu diante de homens e/ou mulheres; realizar tarefas nu ou seminu; maus-tratos verbais e xingamentos de cunho sexual; obrigar as pessoas a permanecer nuas ou seminuas e expô-las a amigos, familiares e/ou estranhos; ausência de intimidade ou privacidade no uso de banheiros; negar às mulheres artigos de higiene, especialmente durante o período menstrual; e ameaças de violação sexual como as anteriormente mencionadas (CNV, 2014, p. 419-420).
\end{abstract}

É importante ressaltar que essa construção semântica do conceito de violência sexual nasce a partir dos próprios relatos das pessoas torturadas. Sendo assim, todas as práticas apresentadas acima fazem parte da sua experiência de vida e da sua memória. Fosse o conceito forjado de modo teórico e abstrato, não seria capaz de identificar e representar o seu sofrimento. Por isso a importância de se buscar um estudo criminológico que reconheça a perspectiva de gênero no cometimento de crimes, o que leva à escolha pelo caminho da crimino logia feminista.

No campo de estudos da criminologia feminista, o empirismo feminista, o ponto de vista feminista (standpoint) e o feminismo pós-moderno são as três epistemologias principais que servem às pesquisas (MENDES, 2014). Para visibilizar a perspectiva de gênero nos crimes cometidos durante o período ditatorial no Brasil, na tentativa de evitar a perpetuação das violências de gênero e sexual e a marginalização das vítimas, as metodologias oferecidas pelo ponto de vista feminista são as mais adequadas ao propósito do artigo ${ }^{3}$.

Compondo a teoria crítica, o ponto de vista feminista posiciona-se politicamente e pretende apontar a visão androcêntrica na construção da realidade e da própria ciência. Para tanto, entende as mulheres como sujeitos forjados na história e ressalta as suas experiências frequentemente desvalorizadas e apagadas nas pesquisas científicas (MENDES, 2014).

Partindo-se dessa premissa metodológica, visibilizar o gênero nos crimes sexuais cometidos durante a ditadura civil-militar implica em "trazer as mulheres para o centro" (CAMPOS, 2012, p. 36), provocando-se, tanto na perspectiva oferecida pela justiça de

\footnotetext{
${ }^{3}$ Ainda segundo Mendes (2014), o empirismo feminista entende que o sexismo e o androcentrismo, apesar de componentes da ciências, são corrigíveis pela utilização de normas metodológicas tradicionais, não aparecendo na identificação e definição de problemas de pesquisa, mas tão somente na comprovação e interpretação dos dados coletados. Já o feminis mo pós-moderno questiona a universalidade do conhecimento e objetiva, através de umolhar desconstrutivista,
} 
transição como na perspectiva de análise do direito ou das categorias jurídicas, uma ruptura com um duplo silenciamento perpetrado pela ausência de tal abordagem nesses campos.

Além de propor novos temas criminológicos, a criminologia feminista pretende-se uma corrente epistemológica inquiridora da definição do objeto de estudo e de seus modos de questionar a realidade. A criminologia feminista traz ainda a resistência a teorias totalizantes, admitindo as perspectivas particulares do sujeito conhecedor e do conhecimento situado, sendo que o que se conhece, e como se conhece, depende da situação e da perspectiva do sujeito conhecedor (MENDES, 2014, p. 85). Nestes mesmos termos, defende Campos (2012) que um estudo que pretenda o reconhecimento da perspectiva de gênero nos crimes cometidos durante a ditadura civil-militar no Brasil não é suficientemente caracterizável como um estudo feminista, pois é necessário também que a crítica ao direito seja produzida por feministas ou que utilize predominantemente referenciais teóricos feministas ${ }^{4}$.

Tradicionalmente, a criminologia crítica e até mesmo a criminologia feminista relacionam a invisibilização da violência de gênero à violência doméstica, em que as mulheres são violentadas por parentes próximos, essencialmente do gênero masculino, a partir de uma relação inicial de confiança e intimidade. No entanto, as violências de gênero e sexuais cometidas durante o período ditatorial vêm revelar outras facetas dessa invisibilização, demonstrando que também o poder institucional parte de uma premissa de inferioridade feminina ou de inferiorização pelo feminino. Trata-se, nesse sentido, de uma ideologia política praticada por agentes do Estado, em uma espécie de arma de guerra, negada pelo ocultamento dos crimes de gênero e sexuais pelo termo generalizante de "tortura". Se há violência contra as mulheres dentro de casa e na rua, houve também nos porões da ditadura, perpetrada por agentes do Estado, pelo poder institucionalizado.

Talvez a principal dificuldade para o reconhecimento de uma perspectiva de gênero nos crimes sexuais cometidos no período esteja relacionada também aos mecanismos utilizados para levantar dados relacionados aos delitos. Em geral, os crimes sexuais são "sempre cometidos às escuras, sem que haja testemunhas. A esse aspecto soma-se a frequente ausência de vestígios, detectáveis por prova pericial, observado o decurso do tempo havido entre o abuso e a narrativa da vítima à polícia" (GONÇALVES, 2016, p. 17). Essas circunstâncias tornam-se ainda mais graves em um contexto tal qual o instaurado a partir de

\footnotetext{
${ }^{4}$ As autoras deste trabalho posicionam-se politicamente em relação às violências político-institucionais sofridas pelas mulheres no período ditatorial e procuram aqui evitar homem-nagens, utilizando principalmente teóricas feministas na consecução do trabalho.
} 
1964, em que as denúncias vieram à tona anos mais tarde, muito em razão dos grandes traumas sofridos pelas vítimas.

Ademais, o cuidado com a questão da não revitimização, frequente com a exposição de relatos, complexifica a tipificação jurídica mais específica e apropriada para os crimes sexuais, vez que "a inexistência de vestígios físicos, aliada à falta de testemunhas presenciais, acaba por determinar a valorização da palavra da vítima, favorecendo a sua exposição a inúmeros depoimentos no afã de produzir a prova e possibilitar a condenação do acusado" (GONÇALVES, 2016, p. 17).

Some-se a isso, ainda, insistindo-se na necessária abordagem metodológica sob o ponto de vista feminista, a crítica à tipificação inadequada realizada aos crimes sexuais cometidos no período. Relatos das vítimas deixam evidente o caráter sexista das práticas de tortura contra as mulheres, mas também contra os homens quando na pretensão de sua inferiorização, a partir de torturas que objetivavam humilhar sua dignidade sexual femininizando-o. Tal conclusão fica clara quando se tem acesso aos muitos depoimentos que estão registrados no já mencionado Relatório da Comissão Nacional da Verdade. Ao ler os relatos, fica evidente que os constrangimentos verbais dirigidos aos homens passavam pela intenção de feminilização e homossexualização simbólica do corpo torturado, conforme narra Miguel Gonçalves Trujillo Filho, preso no DOI-CODI de São Paulo, em outubro de 1975:

\begin{abstract}
O empalamento [muito utilizado como forma de tortura] era um cassetete de borracha com fio elétrico dentro que se introduzia na vagina das mulheres ou no ânus das mulheres, dos homens. Eu não passei por essa coisa [...] Um conhecido meu, ele sofreu esse empalamento e os caras deramchoque nele, e acontece que pelo cassetete, a posição e tal afetou a próstata e ele teve uma ejaculação. Esse torturador, ele viu aquilo, levantou - isso o meu amigo nos contou - viu aquilo, levantou, passou a mão no esperma no chão, passou a mão no rosto, tal... lambeu, [...] é um degenerado, psicopata, misógino, muito violento com as mulheres (CNV, 2014, p. 413).
\end{abstract}

Este relato, como tantos outros que podem ser encontrados no referido Relatório, mais uma vez traz à tona a urgência em abandonar a fundamentação destes crimes como motivados sexualmente. Não o foram, seguem não sendo. São crimes motivados por questão de gênero e sustentados dentro de uma estrutura social e institucional em que os poderes são exercidos com base no menosprezo e/ou subjugação do feminino. Por tais razões, entre outros aspectos, convoca-se a um (re)posicionamento pela teoria criminológica feminista, já que esta reconhece que as experiências das mulheres são, em grande parte, construídas na literatura jurídica e histórica por discursos legais e criminológicos androcêntricos, vez que a legislação e os saberes da criminologia são desenvolvidos por homens. 
Ao considerar, portanto, que "o direito cria subjetividades tanto quanto posições do sujeito" (CAMPOS, 2012, p. 35), observa-se que o conhecimento sobre os crimes sexuais no período ditatorial é forjado sem a perspectiva das mulheres que sofreram essas violências, prejudicando políticas de evitamento de condutas semelhantes no futuro. Posicionadas pela (re)leitura crítica desses crimes cometidos no passado, preocupadas com o legado e a manutenção do não-lugar do feminino seja na abordagem teórico-criminológica, seja na jurisdicionalização destas práticas criminosas mesmo após a democratização no Brasil, apresenta-se, na sequência, o "estado-da-arte" atual das violências de gênero e sexual e de seu enfrentamento.

\section{A VIOLÊNCIA QUE FALA POR SI: UM MAPA GERAL DAS PRÁTICAS DE PERPETUAÇÃO DAS VIOLÊNCIAS DE GÊNERO E SEXUAL}

É possível perceber a perpetuação da violência de gênero pelos agentes públicos no Brasil mesmo em períodos democráticos. Desde normativas que ou ignoram as perspectivas de gênero ou caem no limbo da "positivação sem instrumentos de eficaz garantia e eficaz alcance", passando pela falta de regulamentação e de promoção de políticas públicas, até as violências explícitas - como o tratamento policial oferecido a trabalhadoras sexuais, travestis, mulheres trans, mulheres negras e mulheres pobres - o gênero, como categoria de poder, é utilizado pelo Estado para demarcar a hierarquização entre seres humanos, controlando, por esse marcador, o acesso à cidadania.

Mais uma vez, o Relatório da Comissão Nacional da Verdade vem ao encontro deste diagnóstico quando, ao discutir que as relações sociais de gênero diferenciam as pessoas ou distinguem e norteiam a vida de cada indivíduo, diz ser inevitável constatar que "ambas, normas e relações sociais, envolvem oportunidades, liberdades e obrigações associadas ao ser masculino e ao ser feminino que podem gerar discriminação e, portanto, não favorecer a igualdade, tampouco a liberdade (CNV, 2014, p. 401).

Em termos de normativa internacional, não se pode negar que há uma preocupação em positivar direitos específicos em relação a práticas antidiscriminatórias. A Carta das Nações Unidas, assinada em 1945, trata dos propósitos da instituição, e assim estabelece seu art. $1^{\circ}$ : “conseguir uma cooperação internacional para resolver [...] promover e estimular o respeito aos direitos humanos e às liberdades fundamentais para todos, sem distinção de raça, sexo, língua ou religião". 
Também a Declaração Universal dos Direitos Humanos, adotada pela Assembleia Geral da ONU em 10 de dezembro de 1948, expressamente reconhece que "todos são iguais perante a lei e tem direito, sem qualquer distinção, a igual proteção da lei’. A Convenção Americana sobre Direitos Humanos, assinada em 1969, também estabelece em seu art. $5^{\circ}$ que toda pessoa tem o direito de ter respeitadas sua integridade física, psíquica e moral: "Ninguém deve ser submetido a torturas, nem a penas ou tratos cruéis, desumanos ou degradantes. Toda pessoa privada da liberdade deve ser tratada com o respeito devido à dignidade inerente ao ser humano".

Pode-se dizer que os atos de violência sexual vem evoluindo como objeto de explícita proteção internacional há praticamente um século - ainda que esse esforço só comece a ganhar forma com o Protocolo e as Convenções de Genebra e a Declaração sobre a proteção da mulher e da criança em estados de emergência e de conflito armado.

Ainda, denominada "Lei Internacional dos Direitos das Mulheres", ao desvincular a discriminação contra a mulher de outras discriminações, como as de caráter étnico ou religioso, por exemplo, a Convenção sobre a Eliminação de Todas as Formas de Discriminação contra a Mulher (conhecida pela sigla em inglês "CEDAW"), tornou-se, em 1979, o primeiro tratado internacional a enfrentar a questão de maneira autônoma, ainda que sem fazer menção à violência. $\mathrm{O}$ tema foi inserido uma década depois, quando o comitê dessa Convenção emitiu recomendação para a inclusão de informação, nos relatórios elaborados pelos Estados-parte, sobre a violência (inclusive sexual) praticada contra as mulheres e as medidas que vinham sendo adotadas para lidar com ela. Três anos mais tarde, com a Recomendação n. 18, o mesmo comitê aprofundou sua preocupação ao indicar que a definição de "discriminação contra a mulher", utilizada no artigo $1^{\circ}$ da Convenção, inclui a violência baseada em diferenças de gênero e manifestada através de atos que infligem danos físicos, mentais ou sexuais às mulheres (CNV, 2014, p. 416).

Perseguindo o reconhecimento da violência contra as mulheres como violação aos direitos humanos, a Conferência de Viena, realizada em 1993, desempenhou papel importante. Foi por intermédio da Plataforma de Ação de Viena que os Estados tornaram explícita a ideia de que a violência contra a mulher é uma violação aos direitos humanos e que os direitos das mulheres constituem direitos humanos. A Declaração sobre a eliminação da violência contra as mulheres, adotada pela Assembleia Geral das Nações Unidas, não deixa dúvidas sobre o entendimento da comunidade internacional. Diz seu artigo $1^{\circ}$ : 
resultar, dano ou sofrimento físico, sexual ou psicológico para as mulheres, incluindo as ameaças de tais atos, a coação ou a privação arbitrária de liberdade, que ocorra, quer na vida pública, quer na vida privada.

Entendimento similar foi confirmado pelo sistema regional ao qual o Brasil está submetido. Em junho de 1994, a Convenção Interamericana para Prevenir, Punir e Erradicar a Violência contra a Mulher, adotada em Belém do Pará, passou a considerar violência contra a mulher "qualquer ato ou conduta baseado no gênero, que cause morte, dano ou sofrimento físico, sexual ou psicológico à mulher, tanto na esfera pública como na esfera privada". Além da opressão física e psicológica, isso inclui também a violência sexual, "perpetrada ou tolerada pelo Estado ou seus agentes, onde quer que ocorra". Embora sem efeito vinculante, a Plataforma de Ação de Pequim, resultado da IV Conferência Mundial sobre as Mulheres, realizada em 1995, na China, representou compromisso da comunidade internacional com ações capazes de garantir o respeito a esses direitos. A partir dali, disseminouse a ideia de que seria "inevitável adotar o conceito de gênero para lidar com a complexidade da questão, que exige reestruturação da sociedade e de suas instituições para que as mulheres possam ocupar o lugar que thes é de direito, em arranjos igualitários”. Em relação à violência contra a mulher, em situações de conflito armado, a Plataforma reitera a necessidade de implantação de todas as medidas necessárias para proteger as mulheres e fortalecer os mecanismos de investigação, processo e punição dos responsáveis por crimes desse tipo (CNV, 2014, p. 417).

Focando na América do Sul, mais especificamente numa perspectiva de integração econômica e também social, não se pode negar que entre os países do MERCOSUL (Argentina, Brasil, Paraguai e Uruguai, como membros plenos, já que a Bolívia ainda não conclui seu processo de adesão), ainda que em ritmos diferenciados, há importantes avanços legislativos e desenvolvimento de programas e serviços importantes voltados para as mulheres, em busca de superação das consequências do histórico processo de discriminação de gênero. Entre estes avanços, diversos países, entre os quais o Brasil, legislaram sobre direitos reprodutivos e criaram serviços, ainda que em número insuficiente, para atender às demandas das mulheres na área da saúde. Em oposição, com exceção do Uruguai, a legislação penal dos países do MERCOSUL, por exemplo, ainda criminaliza a interrupção voluntária da gravidez.

Em se tratando especificamente de violência contra a mulher, a despeito de o Brasil ser signatário e ter ratificado boa parte das convenções mencionadas anteriormente, o país foi um dos últimos na América Latina a aprovar uma legislação especial introduzindo no cenário 
normativo nacional uma lei para coibir e prevenir a violência doméstica e familiar contra a mulher. Assim, a Lei 11.340/06 - popularmente conhecida como Lei Maria da Penha - foi considerada em 2012, pelas Nações Unidas, a terceira melhor lei do mundo no combate à violência doméstica, criando mecanismos para coibir a violência doméstica e familiar contra a mulher.

Além da Lei 11.340/06, recentemente aprovou-se a Lei 13.104/15 que altera o art. 121 do Código Penal Brasileiro para prever o feminicídio como circunstância qualificadora do crime de homicídio e o art. $1^{\circ}$ da Lei de Crimes Hediondos, para incluir o feminicídio nesta categoria de crime. Outras legislações também se somam ao quadro normativo de proteção e amparo à mulher vítima de violência, tais como: a Lei 12.015/09, que dispõe sobre os crimes contra a dignidade sexual; a Lei 12.845/13, que dispõe sobre o atendimento obrigatório e integral de pessoas em situação de violência sexual; a Resolução n. 1, de 16.01.2014, que dispõe sobre a criação da Comissão Permanente Mista de Combate à Violência contra a Mulher do Congresso Nacional; o Decreto 7.958/13, que estabelece diretrizes para o atendimento às vítimas de violência sexual pelos profissionais de segurança pública e da rede de atendimento do Sistema Único de Saúde; Decreto 7.393/10, que dispõe sobre o funcionamento do Ligue 180 Central de Atendimento à Mulher.

Destacam-se, por fim, os Decretos 1.973/96, 89.460/84 e 678/92, que promulgaram, respectivamente, a Convenção Interamericana para Prevenir, Punir e Erradicar a Violência contra a Mulher, a Convenção sobre a Eliminação de todas as formas de Discriminação contra a Mulher (CEDAW), e a Convenção Americana sobre Direitos Humanos.

Sem a pretensão de uma análise mais pormenorizada dos atos normativos, entende-se pertinente deixar marcado que, como se pode notar, não seria por falta de legislação que as violências de gênero seguiriam sendo cometidas e/ou invisibilizadas. No entanto, os dados falam por si e dizem muito sobre a permanência da violência de gênero institucional e institucionalizada aqui no Brasil.

Em 2014, 47.646 estupros foram registrados no país. Porém, levando em consideração que somente $35 \%$ dos crimes sexuais são notificados, entende-se que esse número é muito maior (FBSP, 2015). Aqui, dois aspectos devem ser destacados. Primeiramente, a questão de os crimes de estupro estarem ligados principalmente às mulheres, o que fica visível pelas pesquisas de vitimização. Na pesquisa realizada pelo Fórum Brasileiro de Segurança Pública (2015), em resposta à pergunta “você tem medo de ser vítima de agressão sexual?", $90 \%$ das mulheres entrevistadas responderam que sim, enquanto apenas 
$42 \%$ dos homens responderam afirmativamente. Em segundo lugar, é importante compreender as causas da subnotificação desses crimes. Apesar de não haver muitas pesquisas sobre o assunto, é possível destacar hipóteses como a ameaça dos parceiros autores das violências e as dificuldades encontradas no acolhimento nas delegacias.

Os relatos de atendimentos violentos nas delegacias para mulheres demonstram exemplarmente as heranças da ausência de uma perspectiva de gênero nos estudos sobre violência institucional. A falta de capacitação e preparação para o acolhimento de pessoas em situação de violência, resulta em mulheres humilhadas pelos agentes estatais no momento do registro policial, além de desencorajadas a seguir com o processo judicial (POMPEU, 2012). As delegacias de combate às violências contras as mulheres, quando existentes na localidade, pois ainda se encontram em número bastante reduzido, dispõem de poucos recursos, pouco pessoal e permanecem disponíveis para atendimento da população em horários reduzidos (MENDONÇA, 2015).

Em caso recente, uma jovem relatou nas redes sociais o abuso sexual que sofreu no Parque da Redenção, localizado na cidade de Porto Alegre, Rio Grande do Sul, bem como o atendimento violento que recebeu na Delegacia Especializada de Atendimento à Mulher da região (UNIVERSITÁRIA, 2015). Após seu relato, diversas mulheres denunciaram, também pela internet, o tratamento dispensado pela polícia às vítimas de violência sexual (FOGLIATTO, 2015).

Por outro lado, a ausência de respostas estatais às milhares de mulheres que morrem anualmente em decorrência de complicações com abortos clandestinos demonstra também o descaso institucional às perspectivas de gênero. Segundo o relatório elaborado pelo governo brasileiro para o evento "Pequim + 20", o aborto clandestino é a quinta causa da morte materna no país: 'El aborto, que en los años 90 era la principal causa de muerte materna, figura hoy en la quinta posición [...]" (BRASIL, 2015).

Tamanho problema de saúde pública não foi suficiente para gerar respostas legislativas ou mesmo de políticas públicas para o tema, sendo o aborto ainda considerado crime no país. Não se trata somente de desconsiderar a mortandade das mulheres em razão dos abortos clandestinos como um problema de saúde pública, mas entender que sua proibição carrega significados de desprezo às suas escolhas e à sua sexualidade.

Por fim, é importante indicar a falta de debate sobre gênero nas escolas, o que incentiva a formação de pessoas que desconsideram essa perspectiva. Aliás, ao impedir essa discussão 
nas salas de aula, como decidiu o Legislativo brasileiro, denominando de forma pejorativa a questão como "discurso de ideologia de gênero" (COMISSÃO, 2014), o Estado toma uma posição política de discriminação às mulheres e a todas as pessoas que sofrem violência em razão de sua identidade de gênero. Como consequência, veta-se propostas pedagógicas com conteúdos sobre sexualidade, diversidade em relação à orientação sexual, relações de gênero e identidade de gênero. Além de formar uma cidadania excludente, possibilita o crescimento da evasão escolar motivada pela orientação sexual ou identidade de gênero.

A despeito de um emaranhado jurídico que impediria ou enfrentaria episódios como os que serão narrados na sequência, já que há legislação específica para tratamento de violência cometida por agentes públicos de segurança (o Decreto 7.958/13, já em vigor durante os dois episódios apresentados), seguem sendo as violações de gênero pelas instituições do Estado brasileiro práticas desvirtuadas em seus motivos e banalizadas em suas consequências.

São os casos de Verônica Bolina e Maria do Rosário Nunes. Verônica é uma modelo e travesti negra agredida pela polícia após ser acusada de agressão a uma idosa. Após ser detida pela polícia, além de ter seu rosto completamente desfigurado e de apresentar diversos hematomas pelo corpo, Verônica teve seu cabelo raspado e as vestes rasgadas, expondo seus seios e parte de suas nádegas, em uma tentativa de humilhá-la pela sua identidade de gênero. As fotos de Verônica ferida e subjulgada foram divulgadas pela internet e o caso repercutiu mundialmente (TUROLLO JR.; BERGAMO, 2015). Maria do Rosário Nunes é deputada federal pelo Partido dos Trabalhadores. Em sessão legislativa, debatia com Jair Messias Bolsonaro, deputado federal pelo Partido Progressista, quando ele afirmou que "só não a estupraria porque ela não merecia" (FALCÃO; GUERREIRO, 2014). Trata-se de um parlamentar atestando que mulheres merecem ser estupradas. Apesar de responder individualmente pela fala (BOLSONARO, 2015), nenhum procedimento foi tomado em relação ao seu mandato. $\mathrm{O}$ caso demonstra que a violência de gênero não se encontra somente nas instituições de atuação direta com a sociedade, como as polícias civil e militar, mas também em altos cargos legislativos. O Estado, tanto em seu aspecto operativo, quanto político, institucionaliza e invisibiliza a discriminação de gênero, acabando por incentivar a prática de violências contra às mulheres.

Portanto, apesar das normativas de proibição da violência de gênero, identifica-se diversas questões que ainda permeiam a sociedade brasileira e resultam em violências de gênero 
institucionais. Assim, a retomada dessa perspectiva no estudo das violências cometidas por agentes estatais tem por objetivo impedir que tais relatos se perpetuem, sendo invisibilizados por outros marcadores criminológicos como "crimes sexuais", "tortura", entre outros.

\section{CONSIDERAÇÕES FINAIS}

"A tortura é um ato tão terrível que é melhor nem falar", responde o superior religioso responsável por ouvir o depoimento de Frei Tito quando ele, já fora da prisão, denuncia as práticas de tortura praticadas contra si pelo delegado Fleury, ainda durante o regime ditatorial.

Essa fala traduz os exatos e paradigmáticos termos nos quais se propõe encerrar a discussão ora proposta: ao mesmo tempo em que a tortura, como forma de violência, é algo que se deve combater e abolir, é, por outro lado, algo do qual não se deve falar. Da mesma forma, as violências de gênero e sexual cometidas durante o período ditatorial é algo que não se admitir repetir, contudo, não há como evitar e/ou combater aquilo que, supostamente, "não houve".

É assim que se trata a questão das violências cometidas durante o regime ditatorial no Brasil e se projeta a invisibilidade quando se trata das violências de gênero e sexual cometidas durante o regime ditatorial no Brasil. Não há quando sobre o fato não se pode falar.

Há uma incompletude no processo de transição no Brasil por diversos motivos. Segue em vigor uma Lei de Anistia que, tendo sido interpretada como "ato de perdão" geral e irrestrito, permite que as práticas do passado sejam banalizadas no presente. Mantém-se em formação e atuação uma polícia que é militarizada e que recebe como legado os ranços do autoritarismo do passado como se o presente fosse sua manifestação em essência (e aquilo que é, "em essência", não se pode desvirtuar).

Enquanto não houver a coragem de abrir a "caixa de pandora da ditatura" no Brasil, enquanto não se permitir que se processem e julguem as pessoas que cometeram crimes na ditadura, enquanto não se olhar para as práticas de violação dos corpos das mulheres como violência de Estado, não haverá ordenamento jurídico que dê conta de superar as marcas da ausência de memória e verdade em relação a esses crimes no passado. Não é, portanto, a causa de invisibilização das violências de gênero e sexual, a ausência de legislação. Está na origem, no passado do qual não se fala mas que se repete, às avessas de um estado democratizado, está no modus operandi do qual não se abre mão em nome da manutenção de 
uma estrutura androcêntrica e violenta. Não se trata de um debate que deva estar presente somente na produção legislativa, mas sim de questões a serem consideradas na aplicação das leis e na constituição das instituições estatais. A perspectiva de gênero, nesse sentido, deve ser considerada na formação de todo e qualquer agente estatal, sob pena de o Estado ser o próprio violador da dignidade de gênero.

A consequência imediata e latente dessa ausência de enfrentamento do passado pode ser apontada quando se analisa a frequência com que as violências de gênero aparecem ligadas à violência doméstica em grande parte das pesquisas no Brasil. Pouco há de produção sobre as violências de gênero institucionalizadas, levando-nos à impressão de que a questão de gênero seria tão somente uma perspectiva cultural íntima e individual. A concepção de gênero como uma categoria de poder, no sentido foucaultiano amplo trazido por Scott, permite entender porque as violências sofridas pelas mulheres durante a ditadura envolviam a humilhação do seu gênero e uma crítica às expectativas que ele provoca. Aliás, somente essa interpretação dos significados de gênero é capaz de explicar porque os homens eram violentados de forma a femininizá-los no período, ou porque os agentes estatais entendiam o gênero uma categoria capaz de deflagrar violências, ou, ainda, porque o gênero feminino e, portanto, sua imposição a pessoas de outros gêneros são humilhantes e servem à violações sexuais como método de tortura.

Enquanto insistirmos no "disfarce" dos crimes sexuais, tragicamente persistentes, inclusive em períodos democráticos, as violências de gênero e sexual seguirão se reproduzindo com frequência e contribuindo para tornar as vítimas invisíveis e/ou marginais. O fato de os crimes terem sido cometidos por agentes públicos encarregados de proteger a sociedade, a vida e a integridade física de seus cidadãos aumenta o sofrimento da maioria dos sobreviventes, que ainda padecem ao lidar com o estigma em torno dos crimes sexuais, a indiferença da sociedade e a impunidade dos violadores. Urgente que se crie um "capítulo específico" sobre as violências sexual e de gênero nos processos de resgate da memória e da verdade inseridos na justiça de transição. Fazer isso é como que tirar da generalização das violências e dar visibilidade a uma de contornos específicos e que precisa ser tratada dessa forma. De acordo com Kaufman (2010, p. 10), sem a dimensão de gênero, nenhum movimento histórico ou discurso emancipatório é verdadeiro. Todo movimento emancipatório ou revolucionário, ou até distributivo, tem que ter como garantia a emancipação da questão de gênero. 


\section{REFERÊNCIAS BIBLIOGRÁFICAS}

BAICA, Soledad González; FERNÁNDEZ, Mariana Risso (compil.). Las Laurencias. Violencia sexual y de género en el terrorismo de Estado uruguayo. Montevideo: Trilce, 2012.

BANKS, Angela M. Sexual Violence and International Criminal Law: An Analysis of the Ad Hoc Tribunal's Jurisprudence \& the International Criminal Court's Elements of Crimes. Faculty Publications, 2005, Paper 305. Disponível em: 〈http//scholarship.law.wm.edu/facpubs/305〉. Acesso em: 18 mar. 2016.

BOLSONARO é condenado por danos morais ao dizer que Maria do Rosário "não merece" ser estuprada. Ze ro Hora, Porto Alegre, 17 setembro 2015. Disponível em:

$<$ http://zh.clicrbs.com.br/rs/noticias/notic ia/2015/09/bolsonaro-e-condenado-por-danos-morais-aodizer-que-maria-do-rosario-nao-merece-ser-estuprada-4849933.html>. Acesso em: 08 abril 2016.

BRASIL. Poder Executivo. Secretaria de Políticas para a Mulher. Informe nacional B rasil: En el contexto del $20^{\circ}$ aniversario de la Cuarta Conferencia Mundial sobre la Mujer y la aprobación de la Declaración y Plataforma de Acción de Beijing. Pequim, China, 2015. Disponível em:

$<$ http://www.cepal.org/mujer/noticias/paginas/3/51823/Informe_Brasil_Beijing_20.pdf $>$. Acesso em 10 abril 2016.

CAMPOS, Carmen Hein de. Teoria Feminista do Direito e Violência Íntima Contra Mulhe res. EMERJ, Rio de Janeiro, v. 15, n. 57, p. 33-42, jan./mar. 2012.

COMISSÃO aprova texto principal do Plano Nacional de Educação. G1.com, São Paulo, 22 abril 2014. Disponível em: <http://g1.globo.com/educacao/noticia/2014/04/comissao-aprova-textoprincipal-do-plano-nacional-de-educacao.html>. Acesso em 10 abril 2016.

\section{COMISSÃO ESPECIAL DE MORTOS E DESAPARECIDOS POLÍTICOS. Procedimento} adminis trativo CEMDP 114/04. Disponível em:

<http://cemdp.sdh.gov.br/modules/desaparecidos/acervo/ficha/cid/131>. Acesso em: 25 março 2016.

CNV. Comissão Nacional da Verdade. Relatório da CNV. Brasilia, vol. 1, capítulo 10, 2014. Disponível em: http//www.cnv.gov.br/. Acesso em: 20 jan. 2015.

ELÍAS, José. Primera condena en Guatemala por crímenes sexuales en la guerra. El País, 27 fevereiro 2016. Disponível em:

<http://internacional.elpa is.com/internaciona1/2016/02/27/actualidad/1456586852_094828.html>.

Acesso em: 28 fevereiro 2016.

FALCÃO, Márcio; GUERREIRO, Gabriela. Para rebater deputada, Bolsonaro diz que não a 'estupraria'. Folha de São Paulo, Brasilia, 09 dezembro 2014. Disponível em:

$<$ http://www 1.folha.uol.com.br/poder/2014/12/1559815-para-rebater-deputada-bolsonaro-diz-que-naoa-estupraria.shtml>. Acesso em: 9 abril 2016.

FBSP. Fórum Brasileiro de Segurança Pública. 9 Anuário do Fórum B rasileiro de Segurança Pública. São Paulo: 2015. Disponível em:

<http://www.forumseguranca.org.br/storage/download//anuario_2015.pdf>. Acesso em: 13 out. 2015.

FOGLIATTO, Débora. Após estupro na Redenção, outras mulheres relatam descaso policial. Sul21, Porto Alegre, 23 março 2015. Disponível em: $\langle\mathrm{http} / / \mathrm{www}$.sul21.com.br/jornal/apos-estupro-naredencao-outras-mulheres-relatam-descaso-policial/>. Acesso em: 10 abril 2016. 
GONÇALVES, Rafaela Caldeira. Crimes sexuais: visão interdisciplinar. Boletim IBCCrim, São Paulo, n. 280, a. 24, mar. 2016.

INTERNATIONAL AMNESTY. Colombia: scarred bodies, hidden crimes. Sexual violence against women in the armed conflict. 2004. p. 10-11. Disponível em: $<$ https $/ /$ www.amnesty.n1/sites/default/files/public/2004_colombia.pdf>. Acesso em: 11 mar. 2016.

\section{INTERNATIONAL CRIMINAL TRIBUNAL FOR THE FORMER YUGOSLAVIA. Appeal} Chamber, Prosecutor v Kunarac et. al, 12 June 2002. Disponível em: http://www.icty.org/x/cases/kunarac/acjug/en/kun-aj020612e.pdf. Acesso em: 16 mar. 2016.

KAUFMAN, Alejandro. Memoria, violencia y género. In: SONDERÉGUER, María; CORREA, Violeta (comp.). Violencia de género en el terrorismo de Es tado: políticas de memoria, justicia y reparación. Bernal: Universidad Nacional de Quilmes, 2010.

MANTILLA, Julissa. La experiencia de la Comisión de la Verdad y Reconciliación del Perú. In: SONDERÉGUER, María; CORREA, Violeta (comp.). Viole ncia de género en el te rrorismo de Estado: políticas de memoria, justicia y reparación. Bernal: Universidad Nacional de Quilmes, 2010.

MENDES, Soraia da Rosa. Criminologia feminista: novos paradigmas. São Paulo: Saraiva, 2014.

MENDONÇA, Renata. Violência doméstica: 5 obstáculos que mulheres enfrentam para denunciar. BBC Brasil, São Paulo, 10 dezembro 2015. Disponível em: <http://www.bbc.com/portuguese/noticias/2015/12/151209_obstaculos_violencia_mulher_rm>. Acesso em: 08 abril 2016.

POMPEU, Ana. Mulheres agredidas são desencorajadas a denunciar parceiro em delegacias. Correio Braziliense, Distrito Federal, 24 janeiro 2012. Disponível em:

<http://www.correiobraziliense.com.br/app/noticia/cidades/2012/01/24/interna_cidadesdf,287353/mul heres-agredidas-sao-desencorajadas-a-denunciar-parceiro-em-delegacias.shtml $>$. Acesso em: 10 abril 2016.

SCOTT, Joan Wallach. Gênero: uma categoría útil de análise histórica. Educação \& Realidade, Porto Alegre, v. 20, n. 2, jul./dez. 1995, p. 71-99.

SEGATO, Rita Laura. La nueva elocuencia del poder. In: SEGATO, Rita. La escritura en el cuerpo de las muje res as esinadas en Ciudad Juárez. Buenos Aires: Editorial Tinta Limón, 2013.

. Las nuevas formas de la guerra y el cuerpo de las mujeres. In: Revista Sociedade e

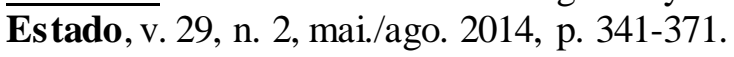

SONDERÉGUER, María; et al. Violencias de género en el terrorismo de Estado en América Latina. Disponível em:

<http://conti.derhuman.jus.gov.ar/2011/10/mesa_9/sondereguer_correa_cassino_gonzalez_mesa_9.pdf >. Acesso em: 11 mar. 2016.

TUROLLO JR., Reynaldo; BERGAMO, Marlene. Travesti fica desfigurada após ser presa e polícia de São Paulo abre investigação. Folha de São Paulo, 16 abril 2015. Disponível em: $<$ http://www 1.folha.uol.com.br/cotidiano/2015/04/1617217-travesti-fica-desfigurada-apos-ser-presa-epolicia-de-sp-abre-investigacao.shtml>. Acesso em: 07 abril 2016.

UNIVERSITÁRIA diz ter sido estuprada à luz do dia em parque de Porto Alegre. G1.com, Porto Alegre, 19 março 2015. Disponível em: <http://g1.globo.com/rs/rio-grande-dosul/noticia/2015/03/universitaria-diz-ter-sido-estuprada-luz-do-dia-em-parque-de-porto-alegre.html . Acesso em 10 abril 2016. 